Fecha de recepción: abril 2019 Fecha de aceptación: octubre 2019 Versión final: diciembre 2019

\section{Brechas y etnicidad. Personajes judíos violentos en películas de Argentina, Uruguay y Venezuela}

Tzvi Tal*

\begin{abstract}
Resumen: Este artículo enfoca la novedosa aparición de personajes judíos que ejercen la violencia en películas producidas en tres sociedades latinoamericanas cruzadas por brechas sociales, políticas y discursivas profundas: Argentina, Uruguay, Venezuela. Partiendo de la premisa que la imagen del judío en el cine puede ser leída alegóricamente como un indicador de los procesos de construcción de la Identidad, al señalar los límites del Nosotros, el Otro incluido y el Otro excluido, el artículo sostiene que este nuevo tipo de personaje judío de ficción cinematográfica expresa la ansiedad que se despierta en las culturas ante la polarización discursiva, que podría desatar la violencia política real. La amenaza no se representa en factores externos, como podría una imagen xenófoba de las nuevas olas migratorias impulsadas por la globalización y el neoliberalismo, sino en el interior mismo de la identidad nacional, a cuya homogeneidad imaginaria contribuía la imagen de la otredad judía incluida y protagonista de filmes. Se refiere a las películas Diablo (Loreti, Argentina, 2011), Relatos Salvajes (Szifrón, Argentina, 2014), Reus (Piñeiro y Fernandez y Pi, Uruguay, 2011), Ms. Kaplan (Brechner, Uruguay, 2014), Esclavo de Dios (Novoa, Argentina - Venezuela - Uruguay, 2013). Salvo Diablo, todas las restantes fueron producidas con apoyo del Programa Ibermedia - Espacio audiovisual iberomericano.
\end{abstract}

Palabras clave: alegoría - brecha - etnicidad - judíos - otredad.

[Resúmenes en inglés y portugués en las páginas 26-27]

${ }^{*}$ Phd. Profesor con nominación permanente. Escuela para las Artes del Sonido y la Pantalla, Colegio Académico Sapir, Israel. Investiga representaciones de la Historia y la reconstrucción de los Héroes nacionales en cine, y la imagen del judío en el cine latinoamericano contemporáneo. Últimos trabajos publicados: 2014: "Memoria histórica y discurso político en Revolución-El cruce de los Andes (Ipiña, 2010)", Cuadernos del Centro de Estudios en Diseño y Comunicación, Universidad de Palermo, Buenos Aires, pp. 241-253. 2015: "Geografía, Memoria e Ideología: los viajes del Che Guevara en películas", Hermeneutic: Revista Digital de Arte, Crítica y Filosofía 13, Universidad Nacional de Patagonia: http://publica ciones.unpa.edu.ar/index.php/1/article/.../155 


\section{Judíos y alegorías}

La inmigración de judíos de Europa Oriental a los países latinoamericanos iniciada en la década de 1880, tuvo una pronta expresión entre los pioneros del cine en el continente. Cineastas, productores y actores judíos participaron en las industrias latinoamericanas del cine desde sus comienzos en los primeros años del siglo XX, a veces bajo seudónimo para ocultar la identidad étnica, otras adaptando los nombres que sonaban raro al castellano y otras sin disimularlo. Sin embargo, los personajes judíos y las temáticas judías aparecieron en las películas de ficción mucho más tarde, supeditadas a los límites que las culturas hegemónicas, primero en las repúblicas oligárquicas y luego en los estados populistas, imponían a las representaciones de la diferencia cultural.

El objeto de este estudio no es un cine étnico, hecho por judíos sobre temáticas judías para consumo por público judío. Son películas producidas en los ámbitos del cine comercial con apoyos de los fondos de estímulo locales y extranjeros, privados o públicos, con actores y personal no necesariamente identificado como judío. Se trata de producciones locales o coproducciones transnacionales, destinadas al consumo por el gran público, que compiten en festivales nacionales e internacionales.

La aproximación al "cine acentuado", donde resaltan las particularidades culturales étnicas y las memorias de la migración o del exilio que los directores expresan en las películas (Naficy, 2001) no es suficiente para comprender este objeto de estudio, donde los cineastas judíos pertenecen a la tercera o cuarta generación desde la migración, donde directores no-judíos realizan filmes enfocando la experiencia judía y donde no se preserva la autenticidad étnica entre los actores y sus personajes. También es problemático referirse a la población latinoamericana judía como minoría étnica, pues a pesar de ser demográficamente ínfima y mantener cierto grado de cohesión basado en lazos familiares, diversos modos de observación de rituales religiosos y conservación de tradiciones culturales, está integrada en las hegemonías nacionales de origen racial blanco europeo, en un continente donde los descendientes de los pueblos originarios y de la población africana esclava siguen sufriendo diversos modos de opresión y discriminación (Tal, 2013).

Los textos audiovisuales difundidos en la cultura popular aportan narrativas e imágenes que son materia prima en la producción de las memorias y las identidades colectivas (Kellner, 1995). También pueden ser interpretados como alegorías que manifiestan discursos sociales en tiempo de su producción, para lo cual el enfoque relevante no es verificar la intencionalidad, sino analizar las referencias al contexto y los usos de los medios de expresión cinematográficos que inducen la producción de la lectura alegórica (Xavier, 1999). Poniendo en juego conocimientos previos y sensibilidad estética, la práctica de la lectura alegórica es parte de las estrategias de construcción de la subjetividad, donde se manifiestan las ideologías. La lectura alegórica de los textos audiovisuales puede desnudar las relaciones entre las retóricas características de los discursos hegemónicos y las prácticas de reconstrucción de las identidades subalternas en la era multicultural. Siguiendo la idea que la Nación es la comunidad imaginada mediante la Narrativa impuesta a la sociedad por el discurso hegemónico, en cuyas fisuras e intersticios se desarrollan las narrativas que dan sentido a la presencia del Otro (Anderson, 1993; Bhabha, 1999), interpretamos la imagen 
del judío en el cine como indicador de los procesos de construcción de la Identidad, que señala los límites de la Nación y manifiesta las ansiedades ante las diferencias y el porvenir.

\section{La imagen del judío y la violencia política}

El "Cine de la experiencia judía" es un término generalizador que es útil para clasificar filmes de acuerdo a protagonistas judíos o según narrativas que enfocan conflictos particulares del judaísmo. Toda aparición de personajes judíos y sus circunstancias quedan así integrados al campo de la investigación (Rosenberg and Whitfield, 2002). Estas imágenes aparecen en las películas latinoamericanas de ficción con creciente frecuencia. En Argentina en algunos de filmes producidos desde los años cuarenta y especialmente en decenas de películas producidas desde los noventa; en Uruguay con las contemporáneas Whisky (Rebella y Stoll, 2004), Acné (Veiroj, 2008), Reus (Piñero, Fernandez y Pi, 2011) y Mr. Kaplan (Brechner, 2014), mientras que la primera aparición registrada de personajes judíos en película ficcional de Venezuela es Esclavo de Dios (Novoa, 2013).

Una diferencia estructural contrapone las películas argentinas de la experiencia judía con las de otros países latinoamericanos. Estas últimas suelen representar la experiencia judía en modo costumbrista que preserva la diferencia cultural y la alteridad atenuada e incluida. Los ritos judíos son visualizados como análogos a los característicos de las culturas nacionales, en una estrategia de equiparación que neutraliza la Otredad: el duelo por los muertos, ritos de pasaje adolescente Bar Mitzvah y escenas de la vida familiar. Casi nunca representan los aspectos institucionales de la experiencia judía y generalmente evitan los rituales que pueden provocar rechazo, como la circuncisión, la preparación del cadáver para el entierro, el divorcio rabínico (Tal, 2013). Por otro lado, la imagen de la experiencia judía en el cine argentino a partir de la democratización de los años ochenta, expresa el impacto de la dictadura y el terror estatal, del neoliberalismo, de los ataques terroristas, la crisis económica y el kirchnerismo, transformando la imagen otrora marginal del judío - de la cual Los gauchos judios (Jusid, 1974) es una excepción-, en alegoría de la argentinidad que se sobrepone a las consecuencias de las vicisitudes y traumas, ya que las particularidades culturales no problematizan la representatividad social de las imágenes (Tal, 2010). En las cinematografías de la experiencia judía de Argentina , Uruguay y Venezuela se percibe la clara diferencia entre las documentales y las ficcionales. La memoria y el pasado histórico de los judíos antes de la migración o durante la integración, son enfocados preferentemente en el cine documental, como Progrom en Buenos Aires (Szwarcbart, Argentina, 2007), El barrio de los judios (Rodriguez Fábrega, Uruguay, 2011) y Los venezolanos judios: diversos orígenes, un mismo destino (Cañas Azuaje, Venezuela 2002), películas donde no faltan referencias y fragmentos documentales de las persecuciones en Europa y la migración. En cambio, los conflictos del presente son enfocados por el cine de ficción, con narrativas que transcurren en ámbitos de la clase media y donde la ausencia de agresividad física manifiesta la inclusión en la ciudadanía y la multiculturalidad. Sin embargo, películas recientes de los tres países difunden imágenes inéditas en sus cines, de personajes judíos que ejercen la violencia física contra sus antagonistas, por sí mismos o mediante 
vicarios. Esta nueva visión de la experiencia judía coincide con la profundización de las brechas sociales y discursivas que polarizan las sociedades.

Viejos estereotipos culturales con raíces en el antisemitismo europeo, atribuían al judío pasividad, debilidad física, intelectualismo exacerbado, de modo que, también en el cine, se feminizaba la imagen del "Otro", cuya inclusión en el cuerpo social requería someterlo a la cultura hegemónica, construyendo la etnicidad subalterna (Bartov, 2004; Abrams, 2012). Adoptando la idea sobre la ética de la Otredad en situaciones de violencia política, genocidio y autoritarismo planteada por la investigación de la imagen del judío en la literatura latinoamericana (Graff Zivin, 2008), asumimos que en las películas aquí tratadas, las imágenes del judío articulan el desafío de la representación de la violencia. El repudio al uso de la violencia para dirimir conflictos políticos es difundido por el discurso de los derechos humanos y compartido por el grueso de las sociedades. Las brechas discursivas contemporáneas expresan con este nuevo tipo de personaje de ficción judío, la ansiedad generada por la polarización que podría desatar violencia. La amenaza no se representa en factores externos, como podría ser una imagen xenófoba de las nuevas olas migratorias impulsadas por la globalización y el neoliberalismo, sino en el interior mismo de la identidad nacional, cuya homogeneidad imaginaria consolidaba la integración de la otredad judía en filmes anteriores.

\section{La Grieta argentina}

El discurso social argentino sufre en los últimos años una polarización denominada popularmente La Grieta, a la que se atribuyen consecuencias perjudiciales en los contactos cotidianos entre las personas. Los discursos en pugna que alternaron en el poder estatal, el kirchnerismo y el macrismo, no lograron cambiar las condiciones de explotación de las mayorías y causan frustración, pero por medio de La Grieta, sus discursos confieren a las personas un motivo para sentirse diferentes, especiales y únicos; son discursos atrayentes y adictivos. La Grieta se expresa en la duda y la desconfianza mutua entre discursos, genera sospechas conspirativas en una sociedad donde la violencia esta enraizada y latente. La duda y la sospecha alimentan el estado de ánimo que en circunstancias provocativas libera la violencia latente (Korstanje, 2016).

La Grieta es la conflictividad social que se expresa en los judíos cinematográficos violentos. En Diablo el boxeador Marcos Weisemberg cultiva la fuerza física y lleva la identidad híbrida grabada en el propio cuerpo: es circunciso, de padre peruano, lleva a Perón y Evita tatuados sobre el pecho, visibles en un semidesnudo que no es frecuente en personajes judíos. Su apodo "El Inca del Sinaí" conjuga lo peruano con lo judío, pero también con lo argentino, parafraseando el apodo "El toro salvaje de las pampas" del boxeador Luis Firpo considerado "padre del boxeo argentino". Weisemberg elimina violentamente narco-traficantes y combatientes de los servicios de seguridad en una narrativa que enfoca el comercio de órganos humanos, apuntando a la corrupción y la impunidad con que funcionarios del estado instrumentan el monopolio legal de la violencia en provecho propio. Es un film hecho para gozar el espectáculo de la violencia, en un género marginal que se produce y circula fuera de los circuitos céntricos, pero obtuvo el primer premio en 
la sección nacional del Festival de Cine de Mar del Plata. Se la equipara con el exceso estético de los violentos filmes norteamericanos de Rodriguez y de Tarantino, pero también se la considera anarco-peronista, enraizada en la vertiente del cine popular argentino de Leonardo Favio (Vieytes, 2015; Silva, 2015; Tabarrozi, 2007).

La violencia latente estalla en cada uno de los seis episodios que componen Relatos Salvajes, cuyo éxito fue acompañado por la división entre los que gustaron de ella y los que la repudiaron, repercutiendo la Grieta. En tres episodios los protagonistas son judíos: el primero, el cuarto y el último. Dos de los protagonistas no tienen mas características étnicas que el apellido: el resentido social Pasternak, que asesina a todos los que le arruinaron la vida precipitando el avión que comparten sobre sus propios padres, y el ingeniero Simón "Bombita" Fisher, que explotando la playa municipal de coches acarreados se convierte en héroe popular de la protesta por la burocrática indiferencia del estado y sus instituciones para con el ciudadano. La novia Romina del último episodio no vacila en agredir físicamente durante la fiesta de casamiento, ostentosamente argentino-judía, a la invitada que tuvo un affaire con su novio. El esquema de episodios en Relatos Salvajes sugiere que la experiencia argentina esta vertebrada y enmarcada por las narrativas de personajes judíos. De este modo, Diablo y Relatos salvajes dan cuenta alegóricamente de la Grieta discursiva que aqueja a la sociedad argentina, donde políticos y funcionarios judíos ocupan posiciones públicas destacadas en ambos márgenes de la misma.

\section{La Grieta uruguaya}

En las películas uruguayas los judíos no ejercen la violencia por si mismos, sino mediante vicarios. Whiskey, Acné y Mr. Kaplan son expresiones de cine étnico tanto por las temáticas como por la identidad étnica de los directores. Enfocan los dramas personales de judíos de clase media casi sin referirse a lo social fuera de la película, introducen imágenes de la experiencia judía fáciles de consumir, transcurren en un pasado cercano impreciso que manifiesta la inclinación a la amnesia histórica que prevalece en la sociedad, expresan una identidad uruguaya desterritorializada que aspira a reterritorializarse como multicultural, legitimando la diferencia (Deleuze y Guattari, 1997). La decadencia de la pequeña industria textil familiar y de las relaciones entre hermanos en Whisky, y la senilidad del protagonista en Mr. Kaplan que fantasea haber descubierto un viejo nazi oculto en Montevideo contemporánea, sugieren que el pasado dejó de ser trascendente. El despertar de la sexualidad adolescente y el ansia de ser besado por amor en Acné son una alegoría reflexiva del nuevo cine uruguayo que pretende desarrollarse y afirmarse (Tal, 2003; Coutoursie, 2008; Radakovich, 2013). De las tres, solo en Mr. Kaplan la violencia ejercida por otros asoma por momentos: por la bailarina hija del supuesto nazi, que en realidad es un kapo judío que reconstruyó su vida, ahuyentando a Wilson, el policía retirado que cuida del viejo Kaplan, y por Wilson durante el secuestro del supuesto nazi, sugiriendo una problemática instalada en la sociedad pero que la película en clave de comedia no enfoca. En cambio, la violencia abunda en Reus, donde la narrativa del enfrentamiento entre los comerciantes judíos y los delincuentes del barrio da cuenta de la problemática de la inseguridad y el delito. 
Las políticas respecto al alza del crimen y la violencia de los gobiernos del Frente Amplio, en el poder nacional desde 2009, han dado lugar a la etnificación de la pobreza. Los pobres son concebidos como pertenecientes a una cultura diferente mientras que las relaciones de desigualdad estructural quedan ocultas, lo que implica respuestas públicas aparentemente contradictorias en la articulación de las políticas asistenciales y punitivas. Uruguay no se caracteriza por una diversidad cultural significativa, los judíos son una minoría integrada desde tres generaciones o más; en el pasado se concentraban en el barrio Reus de Montevideo. Mientras que la pobreza es visible en Montevideo con más dureza, la etnificación de los pobres desplaza la atención de las causas de la pobreza hacia las conductas de los pobres y lleva a proponer intervenciones focalizadas en territorios o barrios, orientadas a fortalecer presuntas identidades locales o comunitarias. Al emerger la violencia como problema prioritario, se activa la policía comunitaria en los territorios, el patrullaje intensivo y la investigación sobre el crimen, con la intervención de equipos de trabajo social y apelando a la participación de la "comunidad", cuyo sujeto es el "vecino". La etnificación de la pobreza impone a los pobres reconocerse en la imagen estereotipada que las prácticas asistenciales y punitivas les devuelven. El resultado es un grupo de individuos estigmatizados cuya única posibilidad es asumir la imagen que se les crea (Pintos García, 2015).

Este panorama de la conflictividad social está alegorizado en Reus, drama policial que obtuvo gran éxito en el público uruguayo. Veteranos comerciantes judíos liderados por Elías y jóvenes delincuentes pobres comandados por El Tano se confrontan en el barrio donde la policía es ineficaz y corrupta. La ascendencia italiana del Tano no es perceptible mas que por el apodo, él y su pandilla son caracterizados como miembros de la cultura de la pobreza. Sólo la intervención de un experto parapolicial contratado por los comerciantes eliminará a la banda. Frecuentes planos picados desde los techos sobre los que se mueven los delincuentes, evidencian la dimensión territorial del conflicto. La demanda de seguridad es expresada por los comerciantes en interiores sombríos. La diferencia cultural entre pobres y judíos se manifiesta claramente en los espacios particulares, la brecha socio-económico resalta en los decorados, los modos idiomáticos y la banda de sonido. El aspecto más llamativo para este análisis es el paralelismo que crea la película entre los mundos contrapuestos del judío y del crimen. El hijo de Elías, líder de los comerciantes, se prepara para el Bar Mitzvá, la ceremonia de entrada al mundo adulto. Así como la vida delictiva y violenta lleva a la destrucción de la familia de El Tano, jefe de la pandilla, la misión de erradicar el crimen que Elías asume perturba su participación en la ceremonia del hijo. El montaje paralelo entre la festividad en la sinagoga y el interrogatorio violento de un miembro de la banda compara la atadura ritual judía del brazo izquierdo -filacterias, que simbolizan la subordinación del individuo a Dios- con las ataduras del delincuente, cotejando las culturas étnicas a ambos márgenes de la brecha social. La banda es destruida mientras se festeja el ritual del chico en la sinagoga, sin embargo, el plano final sugiere que hemos presenciado sólo una batalla en la guerra entre ambos bandos: el hijo del Tano, ahora huérfano de padre y con la madre presa, queda deambulando por los techos, su destino es similar al de su progenitor. La ambivalencia de Elías, que contrata a otros para ejercer la violencia en su lugar, la diferencia cultural entre los bandos en conflicto y la inoperancia policial, concluyen en la acción punitiva que no afecta las causas estructurales de la pobreza. La representación de la experiencia judía cumple un rol alegórico acrítico, 
legitima la diferencia cultural pero la vacía de significado. Fuera del texto cinematográfico y el conflicto imaginario entre las etnicidades, subsiste la estructura social que produce exclusión, delito y violencia.

\section{La Grieta venezolana}

El proceso de la Revolución Bolivariana encabezada por el finado presidente Hugo Chávez desde 1999 ya se había institucionalizado cuando Nicolás Maduro fue electo presidente en abril de 2013 con una mayoría muy restringida de votos, careciendo de las cualidad carismáticas que habían asegurado el liderazgo de aquél hasta su fallecimiento. Las aspiraciones del proyecto chavista habían sido consagradas en la nueva Constitución de 1999, pero al no poder despertar el mismo grado de entusiasmo popular que su antecesor ya había comenzado a perder, el discurso del gobierno de Maduro incrementó progresivamente la polarización discursiva entre partidarios y opositores, sin lograr contrarrestar la erosión en el respaldo popular que la degradación de la calidad de vida originada en la economía internacional, la inflación, la inseguridad en las calles y el usufructo corrupto del poder por altos funcionarios implicaban. De este modo, no sólo se agravó la brecha entre chavismo y la oposición política tradicional al mismo, sino también se fue consolidando una nueva identidad política chavista-no-madurista (Avellaneda, 2014; Arenas, 2016). Mientras tanto, la República Bolivariana y la República Islámica de Irán desarrollaron vínculos económicos y políticos que no cumplieron las grandes expectativas, pero tuvieron como efecto lateral expresiones de antisemitismo por funcionarios y relaciones tensas entre el Estado y la comunidad judía en Venezuela, agravadas por la crisis diplomática con Israel en 2006 y la posterior suspensión de relaciones en 2008, a tal punto que la dimensión de la ola migratoria de judíos que abandonan el país se conserva como un secreto para evitar críticas chauvinistas y xenófobas (Kourliandsky, 2013; Olmo, 2014; Serfaty y Garrido, 2017).

En el clima de polarización de 2013, se realizó Esclavo de Dios, coproducción venezolana - argentina - uruguaya, opera prima del director, premiada en dos de los festivales donde fue presentada. La narrativa ubicada en 1994 enfoca el intento de cometer un atentado terrorista suicida en Buenos Aires por un islamista de origen palestino, huérfano de la guerra civil de 1975 en Líbano, cuyo padre fue asesinado por colaboracionismo con el espionaje israelí. Fragmentos documentales de archivo intercalados al principio contextualizan la ficción en el conflicto Israel - Palestinos, la revolución en Irán y el atentado en la AMIA. Ahmed fue enviado a Venezuela como "agente islamista dormido" y mientras tanto construyó su familia bajo una falsa identidad árabe-cristiana. Se arrepiente durante los preparativos finales para cometer el atentado, mientras es perseguido por la policía argentina y los agentes del Mossad israelí en Buenos Aires, retornando a Caracas donde es torturado por sus activadores, hasta que llegan los agentes del Mossad que lo buscan. En el tiroteo final sobreviven solo Ahmed y David, el agente del Mossad que lo viene persiguiendo desde Argentina. Son palestino e israelí, musulmán y judío, dos enemigos que tienen en común el servicio a causas inflexibles, tal como lo propone pocos minutos antes del desenlace el montaje paralelo entre Ahmed leyendo el Corán y David leyendo el Viejo Testamento con las filacterias puestas. El plano final del film se aleja de los enemigos que 
coinciden tácitamente en no eliminarse mutuamente, para enfocar el nuevo huérfano de uno de los islamistas abatidos que se aleja con el machete de su padre en mano, augurando que la cadena del fanatismo continuará.

La narrativa del film enfoca la presencia en Venezuela del islamismo estimulado por Irán. La delicada situación de los venezolanos judíos ante el gobierno chavista tiene su correlato desplazando la mayor parte de la narrativa a Buenos Aires y relacionando el uso de la violencia por judíos a los agentes del Mossad, personajes que parecen ser argentinos judíos porteños carentes de características israelíes. Sin embargo, la película aprobada por el Centro Nacional Autónomo de Cinematografía despertó un enconado debate público en Venezuela, circulando acusaciones de ser pro-sionista, propaganda israelí anti-venezolana y apoyada por el Mossad. Los cines que la exhibieron en Venezuela fueron obligados por el Centro a proyectar previamente una película corta pro-palestina que algunos acusaron de antisemita (Manvel, 2013). El clima de polarización política y la intimidación de la comunidad judía ante las posturas de funcionarios chavistas, limitaba la conveniencia de construir personajes venezolanos judíos persiguiendo y eliminando islamistas.

\section{Conclusión}

El análisis de las imágenes de personajes judíos violentos en las películas de los tres países demuestra que identidades étnicas no son sólo los campos donde se construye la particularidad cultural del grupo minoritario, sino que también repercuten los conflictos que conmueven a la población toda. En lugar de manifestar un cine acentuado que daría voz e imagen a minorías, Diablo, Relatos Salvajes, Mr. Kaplan, Reus y Esclavo de Dios aluden a problemáticas de las sociedades latinoamericanas contemporáneas cruzadas por brechas sociales, políticas y discursivas, alegorizando en el Otro judío violento las ansiedades que despierta el eventual estallido de la violencia latente en la exclusión, la injusticia social y el manejo corrupto de la cosa pública.

\section{Bibliografía}

Abrams, N. (2012). The New Jew in Film - Exploring Jewishness and Judaism in Contemporary Cinema. London and New York: I.B. Tauris.

Anderson, B. (1993). Comunidades imaginadas. México: Fondo de Cultura Económica, (1a. en inglés 1983).

Arenas, N. (2016). "El chavismo sin Chávez: la deriva de un populismo sin carisma", Nueva Sociedad 261: 14-22.

Avellaneda, A. (2014). "Venezuela is Buried Under Division and Violence." Caribbean Journal of International Relations and Diplomacy 1: 89 - 97.

Bartov, O. (2004). The "Jew" in Cinema - From The Golem to Don't Touch My Holocaust, Bloomington: Indiana University Press.

Bhabha, H. (1990) (ed.). Nation and Narration, New York and London. 
Coutoursie, R. (2008). "El cine uruguayo contemporáneo: desde El lugar del humo hasta Whisky: Crónica de un nacimiento anunciado". Revista Nuestra América 6: 179-183.

Graff Zivin, E. (2008). The Wandering Signifier: Rhetoric of Jewishness in the Latin American Imaginary. Durham: Duke University Press.

Deleuze, G. y Guattari, F. (1997). Mil Mesetas. Capitalismo y esquizofrenia. Valencia: PreTextos.

Kellner, D. (1995). “Cultural Studies, Multiculturalism and Media Culture”, in: Dines, Gail and Humez, Jean M. (eds.), Gender, Race and Class in Media - A Text Reader, London: Sage, pp. 5-17.

Korstanje, M. (2016). "De la Crisis Financiera en 2001 a la Filosofía de la grieta: la política argentina contemporánea". Reflexiones Marginales 33: http://reflexionesmarginales. com/3.0/de-la-crisis-financiera-en-2001-a-la-filosofia-de-la-grieta-la-politica-argentinacontemporanea/. Consultado 15/7/2016.

Kourliandsky, J.-J. (2013). "Irán y América Latina: más cerca por una coyuntura de futuro incierto", Nueva Sociedad 246: 144-158.

Moya Mena, S. I. "Las relaciones entre Irán y América Latina después de Chávez y Ahmadinejad", Centro de Estudios de Medio Oriente y África del Norte, San José: Universidad Nacional de Costa Rica. web.isanet.org/.../814f7b99-7f55-432d-a176-6c46fc28ee4a.pdf. Consultado 15/07/2017.

Naficy, H. (2001). An Accented Cinema - Exilic and Diasporic Filmmaking. New Jersey: Princeton University Press,.

Manvel, N. "La polémica de la película venezolana Esclavo de Dios: Podría ser retirada de la cartelera por boicot”, Noticias24 04/07/2013, http://www.noticias24.com/venezuela/ noticia/178700/la-polemica-de-la-pelicula-venezolana-esclavo-de-dios-podria-serretirada-de-la-cartelera-por-boicot-fotos-y-video/. Consultado 17/07/2017.

Olmo, G. D., "Los judíos de Venezuela, entre la tolerancia social y el antisionismo chavista", ABC Internacional, 16/04/2014. http://www.abc.es/internacional/20140416/abci-judiosvenezuela-chavismo-201403211855.html . Consultado 15/07/2017.

Pintos García, M. (2015). "Apuntes sobre pobreza, cultura y políticas sociales en el Uruguay actual. La etnologización de los pobres”, Fronteras 8: 89-103.

Radakovich, R. (2013). "Cine nacional en Uruguay", ponencia en Congreso Asociación Latinoamericana de Sociología, Chile: http://actacientifica.servicioit.cl/biblioteca/gt/ GT3/GT3_RadakovichR.pdf. Consultado 15/7/2016.

Rosenberg, J. and Whitfield, S. (2002). “The Cinema of Jewish Experience: Introduction”, Prooftexts 22: 1-10.

Serfaty, I. N. y Garrido, N. L., "Sobre la emigración de venezolanos judíos a Israel: matices de una compleja realidad", Nuevo Mundo Israelita 16/01/2017, http://www.nmidigital.com/ sobre-la-emigracion-de-venezolanos-judios-israel-matices-de-una-compleja-realidad/. Consultado 16/07/2017.

Silva, N., "Diablo", http://hacerselacritica.blogspot.co.il/2012/12/diablo-de-nicanor-loreti. html. Consultado 28/2/2015;

Tabarrozi, M. (2007). "Representaciones de lo identitario e ideología estética en el cine de Leonardo Favio, Fernando Solanas, Leopoldo Torre Nilsson y Alejandro Agreste”, ponencia 
en Jornadas de Investigación en Disciplinas Artísticas y Proyectuales, Universidad de La Plata, http://sedici.unlp.edu.ar/handle/10915/39370. Consultado 15/07/2017.

Tal, T. (2005). “Alegorías de memoria y olvido en películas de iniciación: Machuca y Kamchatka", Aisthesis 38: 136-151.

. (2008). "Migración y memoria: la reconstrucción de la identidad de judíos y palestinos en películas recientes de Chile y Argentina", in: Arabes y judios en Iberoamérica \Similitudes, diferencias y tensiones, Raanan Rein (coord.), Sevilla: Fundación Tres Culturas del Mediterráneo, pp. 417-438.

. (2010). Terror, etnicidad y la imagen del judío en el cine argentino contemporáneo", NuevoMundo Nuevos Mundos: http://nuevomundo.revues.org/index58355. html. Consultado 15/7/2016.

(2003). “Cine y Revolución in 'la Suiza de América' - La Cinemateca del Tercer Mundo en Montevideo". Araucaria 4: 70-92.

. (2013). "Etnicidad y espacio público: la imagen del judío en películas de México y Chile", EIAL 1: 65-82.

Vieytes, M., “¿Un cine anarco/peronista?”, http://hacerselacritica.blogspot.com.ar/2012/12/ un-cine-anarcoperonista-diablo-caetano.html. Consultado 28/2/2015.

Xavier, I. (1999). "Allegory and History", in: Robert Stam and Toby Millar (eds.) A Companion to Film Theory, Malden: Blackwell, pp. 333-362.

\begin{abstract}
This article focuses on the novel appearance of violent Jewish characters in Latin American films from three societies crossed by deep social, political and discursive gaps: Argentina, Uruguay and Venezuela. Starting from the premise that the image of the Jew in the cinema can be read allegorically as an indicator of the processes of the National Identity, by pointing out the limits of cultural Inclusion and Exclusion, the article argues that this new type of cinematographic character expresses the anxiety caused by the polarization of the public discourse, that could unleash political violence. The threat is not represented by external factors, such as a xenophobic image of the new waves of migration in the era of Globalization, but within the National community itself, to whose imagined homogeneity the image of included Jewish Otherness has contributed. It refers to the films Diablo (Loreti, Argentina, 2011), Relatos Salvajes (Szifrón, Argentina, 2014), Reus (Piñeiro and Fernandez y Pi, (Uruguay, 2011), Ms. Kaplan (Brechner, Uruguay, 2014), Esclavo de Dios (Novoa (Argentina / Venezuela / Uruguay, 2013). Except for the first, all the rest were produced with the support of the Iberoamerican Audiovisual Program (Ibermedia).
\end{abstract}

Keywords: allegory - discursive gap - ethnicity - jews - otherness.

Resumo: Este artigo enfoca a inovadora aparição de personagens judeus que exercem a violência nos filmes produzidos em três sociedades latino-americanas cruzadas por brechas sociais, políticas e discursivas profundas: Argentina, Uruguai, Venezuela. Partindo da premissa que a imagem do judeu no cinema pode ser lida alegoricamente como um indicador dos processos de construção da identidade, ao observar os limites do Nós, o Outro 
incluso e o Outro excluso, o artigo sustenta que este novo tipo de personagem judeu de ficção cinematográfica expressa a ansiedade que se desperta nas culturas ante a polarização discursiva, que poderia desatar a violência política real. A ameaça não é representada em fatores externos, como poderia uma imagem xenófoba das novas ondas migratórias impulsas pela globalização e o neoliberalismo, senão no interior mesmo da identidade nacional, a cuia homogeneidade imaginária contribuía a imagem da alteridade judia inclusa e protagonista de filmes. Estes filmes são Diabo (Loreti, Argentina, 2011), Relatos Selvagens (Szifrón, Argentina, 2014), Reus (Piñeiro y Fernandez y Pi, Uruguay, 2011), Ms. Kaplan (Brechner, Uruguay, 2014), Escravo de Deus (Novoa, Argentina - Venezuela - Uruguay, 2013). Excetuando Diabo, todas as restantes foram produzidas com apoio do Programa Ibermedia - Espaço audiovisual ibero-americano.

Palavras chave: alegoria - brecha - etnia - judeus - alteridade. 